\title{
TECNOLOGIA DE PROCESSAMENTO DE SALGA ÚMIDA E SALGA SECA DE FILÉ COM E SEM PELE DE PACU (Piaractus mesopotamicus)
}

\author{
SILVA, Elisângela Fernandes da ${ }^{1}$ \\ HONORATO, Claucia Aparecida ${ }^{2}$
}

\begin{abstract}
RESUMO: O objetivo desse trabalho foi avaliar métodos de salga úmida e seca, para conservação de files com pele e sem pele do pacu. Foram determinados os rendimentos de filé e porcentagens de subprodutos da filetagem. Para a conservação dos filés foi utilizado o filé com pele e o filé sem pele. Esses foram divididos em dois lotes, um destinado para preservação em salga úmida e outro para salga seca. Para a comparação dos resultados as análises estatísticas foram realizadas segundo um delineamento inteiramente casualizado (DIC) com dois tratamentos (produtos) com 15 repetições. Para o estudo de perdas de umidade foi utilizado DIC, em um esquema de parcela subdividida, tendo como tratamento principal os tipos de filés e como tratamento secundário as avaliações a cada $12 \mathrm{~h}$. Os filés perderam durante o processo de salga seca $36 \%$ de peso correspondente ao teor de água. A maior perada de peso foi observada na primeira 24 horas correspondendo a 18,99\% do peso do filé seguido de 10,10\% após 48 de exposição a salga. As maiores peradas foram observadas nas primeiras 48 horas de exposição a salga úmida (28\%). Após 48 horas as perdas foram inferiores a $10 \%$ a cada 24 horas. Concluiu-se que a retirada da pele do filé impacta de forma significativa o rendimento de partes comestíveis do pacu. O método de salga seca pode ser utilizado com grande eficiência para conservação de filés de pacu dando origem a um produto diferenciado para o mercado consumidor.
\end{abstract}

Palavras chaves: Peixes. Conservação do pescado. Piscicultura.

\section{PROCESSING TECHNOLOGY OF WET AND DRY SALTING, BRINING FILLETS WITH AND WITHOUT SKIN OF PACU}

\begin{abstract}
SUMMARY: The objective of this work was to evaluate methods of wet and dry salting to preserve files with skin or skin of the pacu. Were certain the fillet yields and percentages of by-products of filleting. For the conservation of the filets filet with skin and fillet without skin. These were divided into two batches, one destined for preservation in wet salting and another for dry salting. For the comparison of the results the statistical analyses were conducted using a completely randomized design (DIC) with two treatments (products) with 15 repetitions. For the study of moisture losses was used DIC in a plot subdivided, having as main types of fillets and as secondary treatment assessments to each 12:0. The fillets were lost during the dry salting process 36 of weight corresponding to water content. The greatest weight was observed in Perry first 12:0 am corresponding to 18.99 fillet weight followed by 10.10 after 48 of exposure to salting. The largest were observed in Perry first 48 hours of exposure to wet brining (28). After 48 hours the losses were less than 10 each 12:0 am. It was concluded that the removal of skin from the fillet significantly impacts the performance of the edible parts of the pacu. The dry salting method can be utilized with great efficiency to pacu fillets conservation giving rise to a differentiated product for the consumer market.
\end{abstract}

Keywords: Fish. Conservation of fish. Pisciculture.

\footnotetext{
${ }^{1}$ Centro Universitário da Grande Dourados (UNIGRAN), Faculdade de Ciências Biológicas e da Saúde, Hospital Veterinário, Rua Balbina de Matos, 2121 - Jd. Universitário CEP 79.824-900 - Dourados/MS, elisangela_fsna1@ hotmail.com

${ }^{2}$ Centro Universitário da Grande Dourados (UNIGRAN), Faculdade de Ciências Biológicas e da Saúde, Hospital Veterinário, Rua Balbina de Matos, 2121 - Jd. Universitário CEP 79.824-900 - Dourados/MS, clauciahonorato@yahoo.com.br
} 


\section{INTRODUÇÃO}

A aquicultura é uma alternativa para incrementar os índices de consumo de proteínas de origem animal e um importante fator de desenvolvimento sócio econômico para o país (SOUZA, 2002). O consumo de peixes no Brasil é baixo se comparado ao de outros países. São apenas 7 quilos por habitante ao ano, segundo o último estudo realizado pelo IBGE. A média mundial é de $16 \mathrm{~kg} / \mathrm{hab} / \mathrm{ano}$ e o recomendado pela Organização Mundial de Saúde (OMS) é 12 kg/hab/ano.

Os peixes podem ser conservados industrializados ou frescos, entretanto a industrialização do pescado deve estar atenta ao tempo de prateleiras que esse vai ficar exposto. Atenção especial deve ser distendida aos produtos a base de peixe devido ao consumo de peixe no Brasil ainda ser incipiente (BRESSAN, 2001).

Para que o consumo de pescado aumente é preciso que esse produto chegue ao mercado consumidor de forma mais atrativa sem perder as qualidades do produto in natura. A viabilização de novas formas de processamento do pescado pode estimular o consumo e agregar valor ao produto. Para que esse produto tenha maior aceitação no mercado pode-se adotar: a realização da depuração, aplicação de métodos eficientes que retardam a decomposição, sendo esses métodos: a evisceração, seguido de filetagem, ou ainda o filé e os subprodutos podem ser processados usando a dessecagem, defumação e até mesmo a salga (FERREIRA et al.,2002).

Segundo Bressan (2001), o entendimento da composição de alimento de origem animal é indispensável, pois pode determinar a escolha do método de conservação, bem como medidas a serem tomadas para aumentar o tempo de prateleira do produto. A carne do peixe apresenta sal em torno de 0,08 e $1 \%$ em sua composição, quantidade esta insuficiente para sua conservação. Sendo assim, uma das formas que podem ser utilizadas para preservar o pescado é a salga.

Dentre vários métodos de conservação, a salga é um dos métodos mais conhecido para a preservação de alimentos, geralmente sendo mais usada em carnes e pescados. Seu princípio está baseado na utilização de sal que, em concentração correta, pode diminuir ou impedir a decomposição do alimento por autólise ou pela ação de microrganismos. Na salga, o sal provoca uma ação dupla, ao penetrar a carne do pescado, o sal diminui a quantidade total de água existente, com isso, o pescado diminui, contudo o sal permanece no interior do pescado diminuindo água, ou seja, retendo a disponibilidade de água para ação enzimática ou crescimento e proliferação de microrganismos (FERREIRA et al.,2002).

Esse processo de salga trata-se de um encadeamento de reações físicas, químicas e microbiológicas, entre os agentes da salga e as proteínas da carne, que transformam em matéria prima pronta para conservação, preservando aroma, textura, cor e sabor especifico do alimento (BEIRÃO et al., 1996). A conservação por método de salga pode ser definida como salga seca e salga úmida. A salga seca, o processo e feito formando-se camadas homogêneas intercaladas de sal e pescado, na salga úmida o pescado é mergulhado em uma salmoura artificial supersaturada.

Por ser um processo de baixo custo pode ser utilizado com facilidade em locais carentes de infraestrutura pesqueira de armazenagem (SZENTTAMÁSY et al., 1993). Sendo assim, o pacu (Piaractus mesopotamicus), torna-se uma grande opção para o uso desses métodos de processamento e conservação.

O pacu (Piaractus mesopotamicus) é uma espécie nativa que apresenta crescimento rápido, boa aceitação no mercado e pode ser encontrado na América do Sul na Bacia do Prata e Pantanal MatoGrossense. Devido a estas características, esta espécie vem sendo cultivada em várias regiões do Brasil, tornando-se uma espécie importante para aqüicultura e uma boa opção para utilização em processamento (FREITAS et al.,2007). 
O objetivo desse trabalho foi avaliar métodos de salga úmida e seca, para conservação de files com pele e sem pele do pacu (Piaractus mesopotamicus)

\section{MATERIAL E MÉTODOS}

Esse trabalho foi desenvolvido no Laboratório de Técnicas Alimentícias do Centro Universitário da Grande Dourados (UNIGRAN). Foram utilizados 30 pacus com peso de 1103,04 $\pm 70,11$. Os peixes foram abatidos por choques térmicos (segundo as normas de abate e de bem estar para pescado), lavados, pesados em balança de precisão de $0,1 \mathrm{~g}$, decapitados e eviscerados.

Para a determinação dos rendimentos e porcentagens de subprodutos da filetagem, foram pesados os filés sem pele e sem espinhos, músculo abdominal ventral, pele e resíduos da filetagem (cabeça sem as brânquias, vísceras, coluna vertebral e as nadadeiras).

Foram aferidos os seguintes parâmetros: PT - peso total, PCE - peso do corpo eviscerado; PC - peso da cabeça; PF - peso do filé; PS - peso das vísceras + brânquias + carcaça;

Todos os dados de rendimento foram calculados em porcentagem, em relação ao peso total do exemplar. Para a análise do rendimento de carcaça, de filé e de subprodutos, foram utilizadas as fórmulas: Porcentagem de filé $(\% \mathrm{~F})=\mathrm{PF}$ x $100 /$ PT; Porcentagem de Carcaça $(\% \mathrm{C})$ = PCE x $100 /$ PT; Porcentagem de Subprodutos $(\%$ S) $=$ PS x $100 /$ PT.

Para a conservação dos filés foi utilizado o filé com pele e o filé sem pele. Esses foram divididos em dois lotes, um destinado para preservação em salga úmida e outro para salga seca. Para salga úmida foi utilizada a proporção salmoura: filé de 2:1, e os filés permaneceram por seis dias. Durante esse período a cada 12 horas os filés foram pesados e retirados amostra para posteriores análises. Para a salga seca, os filés foram empilhados, sendo intercalados por camadas de sal grosso. O processo foi acompanhado por 96 horas.

O acompanhamento dos processos de salga foi realizado até que o conteúdo de sal no músculo atingisse 14\%. Nos filés foram determinados os teores de umidade segundo a AOAC (2000).

Para a comparação dos resultados as análises estatísticas foram realizadas segundo um delineamento inteiramente casualizado (DIC) com dois tratamentos (produtos) com 15 repetições. Para o estudo de perdas de umidade foi utilizado DIC, em um esquema de parcela subdividida, tendo como tratamento principal os tipos de filés e como tratamento secundário as avaliações a cada $12 \mathrm{~h}$, com 15 repetições.

\section{RESULTADOS E DISCUSSÃO}

$\mathrm{O}$ rendimento de carcaça ficou dentro do esperado para peixes redondos demonstrando que o rendimento do tronco limpo foi de $67,40 \pm 6,0$ (Figura 1), rendimento de filé com pele de 44,3 $\pm 6,3$, rendimento de filé sem pele de $36,3 \pm 9,3$ e rendimento de costelinha de 7,3\% $\pm 3,9$.a retirada da pele do filé provoca uma perda de peso em torno de $9 \%$ do peso total. Contreras-Guzmán (1994) relatou que a pele equivale a 7,5\% do peso dos peixes ósseo, o rendimento de filé com pele, de espécies encontra-se entre $32,8 \%$ e $59,8 \%$, com uma média de $50,5 \%$; visto que, com a retirada da pele, o rendimento de filé caiu para $43 \%$.

Basso e Ferreira (2011) estudando efeito do peso ao abate nos rendimentos dos processamentos do pacu (Piaractus mesopotamicus) descreveram que o rendimento de filé apresenta aumento linear conforme aumenta a classe de peso dos peixes. Outro fator que altera o rendimento de partes comestíveis 
do peixe está a relação entre as partes do corpo como tamanho de cabeça e nadadeiras.

Figura 1 - Percentual de rendimento de carcaça de pacu.

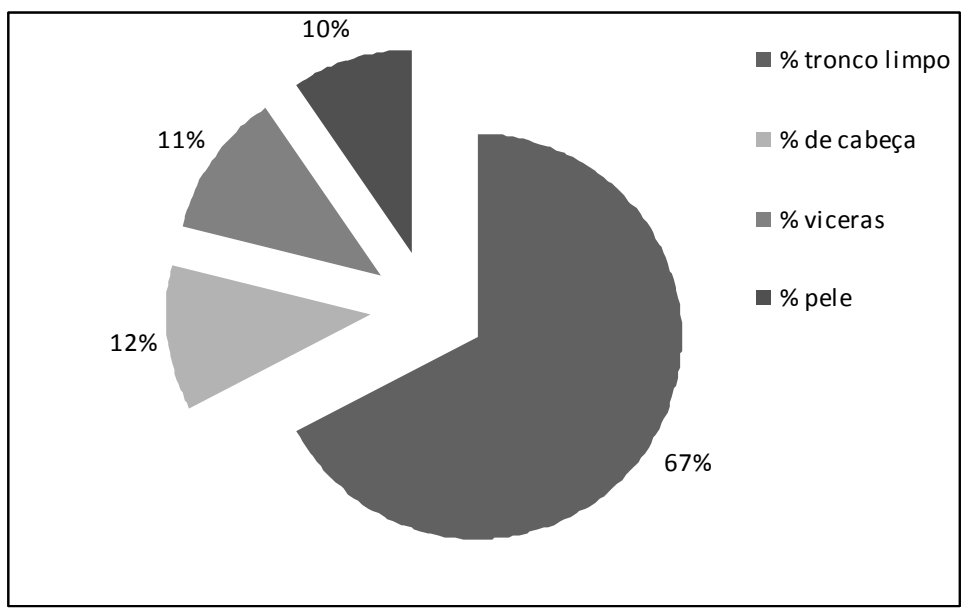

Os rendimentos de filé foram influenciados pela presença de pele, demonstrado que a deixar a pele ao filé apresenta maior rendimento de partes comestíveis. Os rendimentos de filés sem pele do estudo estão de acordo para o pacu com 33\% (Basso e Ferreira (2011).

Conforme Faria et al. (2003) a tilápia apresenta rendimentos de filés com e sem pele $(39,21 \%$ e $36,44 \%$, respectivamente) inferiores ao do pacu (51,60\% e 46,73\% para o filé com pele e sem pele), ao qual estão relacionados principalmente com a morfologia dos peixes. Ressalta-se que as diferenças entre rendimento de filé com e sem pele desses estudos estão relacionadas com o tamanho dos peixes. Basso e Ferreira (2011) descrevem que o pacu apresenta correlação positiva centre tamanho de peixe e rendimento do filé.

Figura 2 - Rendimento de filé e quantidade de descarte do pacu.

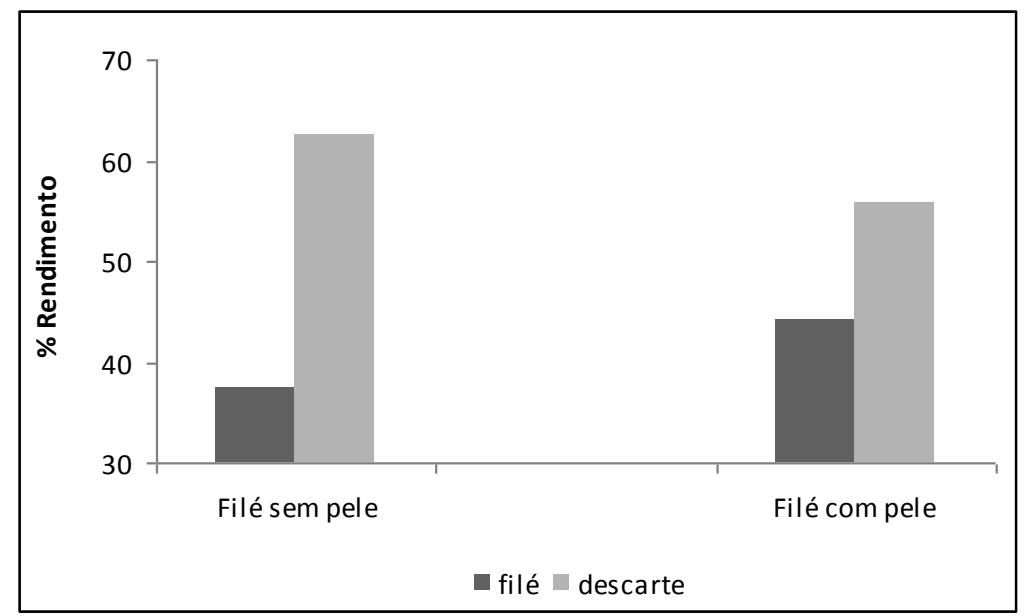

Os filés com pele e sem pele submetidos a salga seca não apresentaram diferença quanto a adequação a perda de água. A perda de água durante o processo de salga foi eficiente para garantir um produto estável à temperatura ambiente. Os filés perderam em torno de $36 \%$ de peso correspondente ao 
teor de água. A maior perda de peso foi observada na primeira 24 horas correspondendo a 18,99\% do peso do filé seguido de 10,10\% após 48 de exposição a salga. Devido à estabilização da perda após 72 horas de exposição, pode-se considerar que esse período é o mínimo para o processamento da salga. A análise de regressão revelou que a presença ou ausência da pele no filé não influencia na dinâmica de perda de água pelo filé sendo ambas adequadas a uma equação quadrática (Figura 3).

Figura 3 - Análise de regressão dos filés (FCP - filés com pele e FSP - filés sem pele) de pacu submetidos a salga seca.

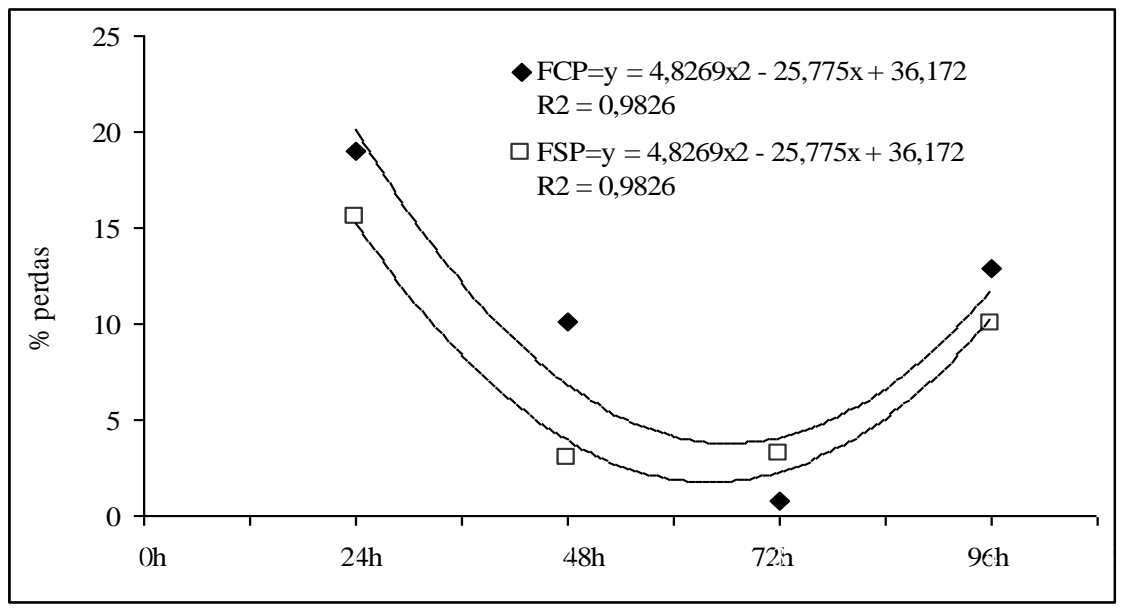

Aiura et al. (2008) observaram que no processo da salga seca para tilápia do Nilo, a queda nos teores de umidade foi mais intensa e linear, atingindo aproximadamente 50\% após 96 horas de salga.

O aumento da umidade após 72 horas de exposição ao processo de salga segundo Ogawa (1999) está relacionado a mudança nas propriedades de absorção de água das proteínas musculares por ação do sal. De acordo com Bressan (2001), a desidratação ocorre pela alta à absorção de cloreto de sódio no tecido do pescado, esta por sua vez deve ser realizada de forma rápida para inibir a deterioração do peixe.

As maiores perdas foram observadas nas primeiras 48 horas de exposição a salga úmida (28\%). Após 48 horas as perdas foram inferiores a $10 \%$ a cada 24 horas. Contudo, a análise de regressão (Figura 4) demonstra que há modulação de perdas de umidade para filés com pele adequada a equação cúbica e os filés sem pele a equação quadrática, revelando então picos de perdas de umidade em tempos diferentes. Os dois tipos de produtos apresentaram perdas que são compatíveis para um produto exposta a salmoura.

Figura 4 - Análise de regressão dos filés (FCP - filés com pele e FSP - filés sem pele) de pacu submetidos a salga úmida.

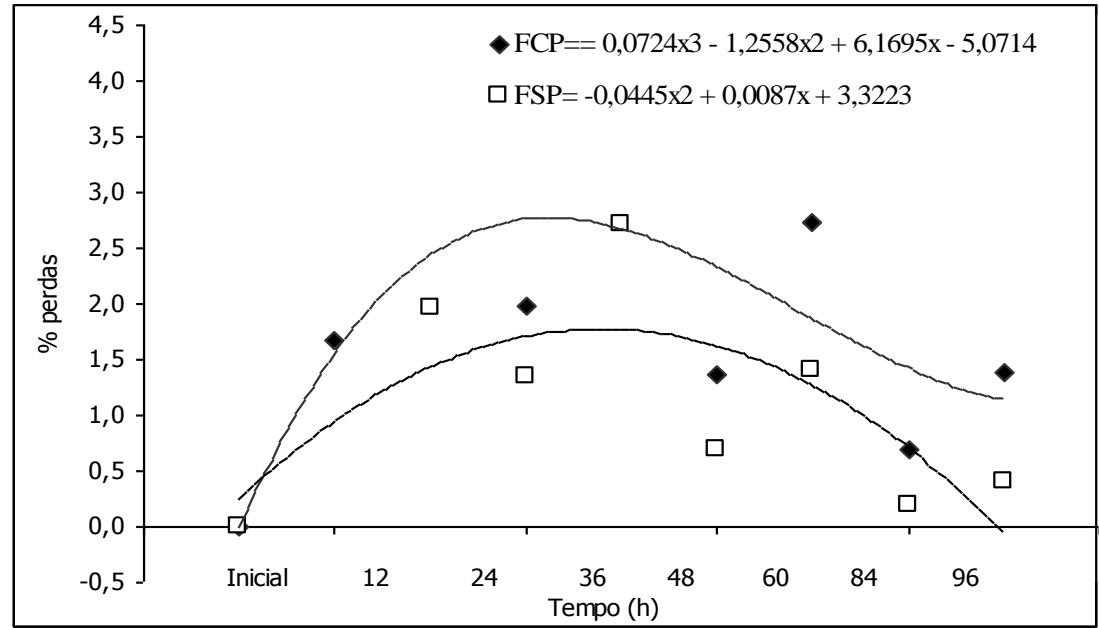


Os resultados obtidos para umidade da salga seca e úmida apresentam-se dentro dos valores esperados Segundo Ogawa e Maia (1999). O aumento de umidade dos filés expostos ao processo de salga úmida deve-se ao enturgecimento das células. No estudo realizado por Freitas et al. (2011) observaram que o processo de salga úmida os filés apresentavam maior percentual de umidade.

Na salga úmida o pescado é mergulhado em uma salmoura artificial super saturada. Nesse caso, as mudanças de peso são bastante complicadas, e dependem muito da espécie processada. O produto obtido pelo processo de salga úmida é de qualidade superior quando comparado com produtos obtidos por meio da salga seca, pois a gordura não entra em contato com o ar, já que está mergulhada na salmoura, e assim a rancificação é bastante diminuída (MACEDO VIEGAS; SOUZA, 2004).

\section{CONCLUSÃO}

Conclui-se que a retirada da pele do filé impacta de forma significativa o rendimento de partes comestíveis do pacu.

O método de salga seca pode ser utilizado com grande eficiência para conservação de filés de pacu dando origem a um produto diferenciado para o mercado consumidor.

O filé com pele foi o que apresentou melhor aparência no processo de salga seca e úmida.

\section{REFERÊNCIAS}

AIURA, F.S.et al. Conservação de filés de tilápia-do-nilo (Oreochromis niloticus) em salga seca e salga úmida. Arq. Bras. Med. Vet. Zootec., v.60, n.6, p.1531-1537, 2008.

BASSO, L.; FERREIRA, M. W. Efeito do peso ao abate nos rendimentos dos processamentos do pacu (Piaractus mesopotamicus). Revista Agrarian, v.4, n.12, p.134-139, 2011

BEIRÃO, L. H.et al. Salga de cação (Squatina argentina) e abrótea (Urophycis brasiliensis).Boletim CEPPA, Curitiba, v. 14, n. 1, p.25-32, 1996.

BRESSAN, M, C. Tecnologia de pós-colheita em peixes. Lavras: UFLA/FAEPE, 2001.

CONTRERAS-GUZMÁN, E. S. Bioquímica de pescados e derivados. Jaboticabal: Fundação

Universidade Estadual Paulista, 1994. 409p.

FERREIRA, M. F. et al. Pescados processados: maior vida de prateleira e maior valor agregado. Boletim de expansão, 2002.

FREITAS, J. M. A.et al. Avaliação do processo de salga úmida e seca do pacu (Piaractus mesopotamicus). In: CONGRESSO BRASILEIRO DE PRODUÇÃO DE PEIXES NATIVOS DE ÁGUA DOCE E, 1. ENCONTRO DE PISCICULTORES DE MATO GROSSO DO SUL, 1. 2007.

FREITAS, J. M. A. et al. Salga seca e úmida de filés de pacu (Piaractus mesopotamicus). Semina: Ciências Agrárias, v. 32, n. 2, p. 613-620, abr/jun. 2011.

MACEDO VIEGAS e SOUZA. Pré processamento e conservação de peixes cultivados. In: CYRINO, J.E.P. et al. Tópicos especiais em piscicultura de água doce tropical intensiva. São Paulo: TecArt, 2004, p.432-445.

OGAWA, M. Tecnologia do pescado. In: OGAWA, M.; MAIA, E.L. (Eds). Manual de pesca: ciência e tecnologia do pescado. São Paulo: Varela, 1999. p.291-299. 
OGAWA, M.; MAIA, E. L. Manual de pesca. Ciência e Tecnologia do Pescado. São Paulo: Varela, v. 1, n. 1, p. 293-299, 1999.

PEREIRA, M. P.; TELLES, E. O.; DIAS, R. A.; BALIAN, S. C. Descrição do sistema agroindustrial brasileiro de pescado. Informações Econômicas, v.40, n.3, mar. 2010. /2010.

SOUZA, M. L. R. Comparação de seis métodos de filetagem, em relação ao rendimento de filé e de subprodutos do processamento da Tilápia-do-Nilo (Oreochromis niloticus). Revista Brasileira de Zootecnia, v.31, n.3, p 1076-1084, 2002.

SZENTTAMASY, E. R.et al. Tecnologia do pescado de água doce: aproveitamento do pacu (Piaractus mesopotamicus). Scientia Agricola, v.50, n.2, p. 303-310, 1993. 
